\title{
ASO Author Reflections: Limiting Axillary Surgery for Microinvasive Breast Cancer
}

\author{
Ted A. James, MD, MS, and Betty Fan, DO \\ Breast Surgery Service, Beth Israel Deaconess Medical Center, Harvard Medical School, Boston, MA
}

Sentinel lymph node biopsy (SLNB) is the mainstay of axillary staging for patients with clinically node-negative, early stage invasive carcinoma of the breast. However, patients with microinvasive disease (DCISM) present with a lower overall risk of nodal metastasis, reducing the potential value of axillary surgery in the majority of these cases. ${ }^{1}$

Our current study evaluated the rate of axillary lymph node involvement in DCISM using the National Cancer Database. Our findings demonstrated that the overall rate of sentinel node metastasis was $2.9 \% .^{2}$ Furthermore, the majority of lymph node involvement was limited to micrometastasis and isolated tumor cells (ITCs). The low rate of node involvement suggests that most patients with DCISM are exposed to the potential risks of axillary surgery without any clinical benefit. ${ }^{3}$

We continue to recommend SLNB for patients undergoing mastectomy and acknowledge the standard practice of SLNB in breast conservation (i.e., lumpectomy). In certain cases, SLNB results may affect adjuvant treatment decisions and should continue to be performed for this purpose. However, our study's findings should factor in clinical decision-making for patients with DCISM, especially when considering returning to the operating room for SLNB in cases where an initial diagnosis of pure DCIS

(C) Society of Surgical Oncology 2020

First Received: 21 May 2020;

Published Online: 2 June 2020

T. A. James, MD, MS

e-mail: ted.james@bidmc.harvard.edu upstages to DCISM on final pathology. There may also be a role for special consideration if there are concerns about morbidity from additional axillary surgery.

Ideally, advances in preoperative clinical assessment would provide new methods for determining the risk of disease in axillary nodes, allowing surgeons to omit SLNB on a routine basis safely. With the vast majority of patients being pathologically node-negative, developing a better selection process for SLNB would reduce the burden of unnecessary surgery while identifying the few patients with DCISM who truly warrant axillary surgery.

DISCLOSURES Ted A. James: Advisor for Perimeter.

\section{REFERENCES}

1. Matsen $\mathrm{CB}$, Hirsch A, Eaton A, et al. Extent of microinvasion in ductal carcinoma in situ is not associated with sentinel lymph node metastases. Ann Surg Oncol. 2014;21(10):3330-5.

2. Fan B, Pardo JA, Serres S, et al. Role of sentinel lymph node biopsy in microinvasive breast cancer. Ann Surg Oncol. 2020. h ttps://doi.org/10.1245/s10434-020-08606-3.

3. Purushotham AD, Upponi S, Klevesath MB, et al. Morbidity after sentinel lymph node biopsy in primary breast cancer: results from a randomized controlled trial. Clin Oncol. 2005;23(19):4312-21.

Publisher's Note Springer Nature remains neutral with regard to jurisdictional claims in published maps and institutional affiliations. 